\title{
Help kick off a summer of smiles
}

\author{
The Oral Health Foundation has \\ announced the return of National Smile \\ Month, which this year will take place \\ between 14 May and 14 June, aiming \\ to increase awareness of important oral \\ health issues and make a significant \\ difference to the well-being of millions of \\ people. \\ Supported by thousands of individuals \\ and organisations, National Smile Month \\ promotes three key messages at the heart \\ of good oral health: \\ - Brush your teeth last thing at night and \\ on at least one other occasion with a \\ fluoride toothpaste \\ - Cut down on how much and often you \\ have sugary foods and drinks
}

- Visit your dentist regularly, as often as they recommend.

The charity is calling on dental, healthcare, education professionals and support from the voluntary sector to help spread smiles and key oral health messages even further than ever before.

Chief Executive of the Oral Health Foundation, Dr Nigel Carter OBE, said: 'Last year, the campaign reached unprecedented levels, with in more than 4,000 organisations pledging their support in promoting better oral health. This year we want it to be even bigger and better.

'Much of the credit for the improvement we have seen in oral health over recent years is down to hard working supporters and volunteers who reach out to their local communities.

'With your support the campaign reaches more than 50 million people each year and we are delighted to see how many of you actively get involved in National Smile Month.'

National Smile Month 2018 sees the return of the now iconic Smiley, something which Dr Carter believes symbolises exactly the purpose of the campaign.

To find out more about the campaign and to get involved, visit www.smilemonth.org.

\section{Cause for applause}

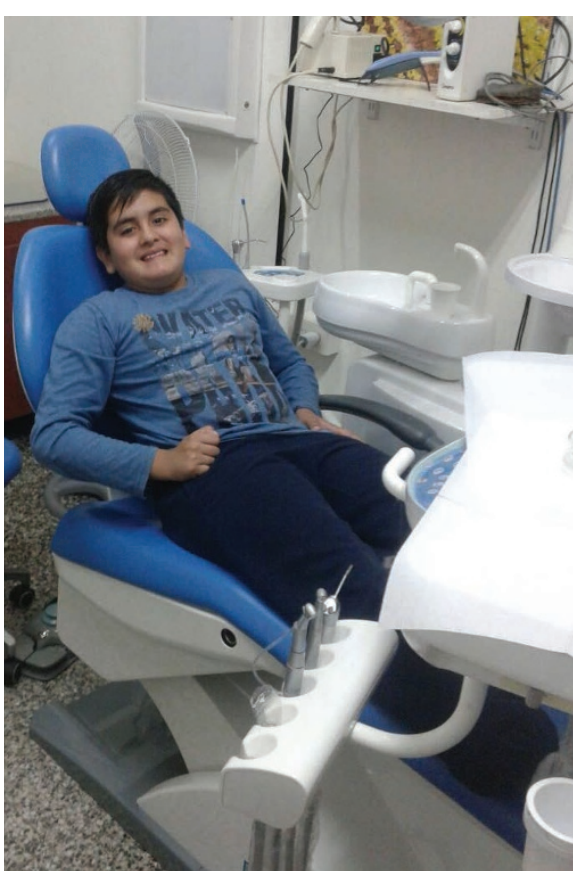

New dental chair for vulnerable children

Children living in the slums of Buenos Aires were very excited to see a brand new dental chair (pictured) roll into their clinic in the autumn when the Alpha Omega London Charitable Trust donated a new dental unit to the Todos Juntos Children's Trust, a dental charity dedicated to providing oral hygiene and dental restoration to the most vulnerable of children in Buenos Aires, Argentina.

Todos Juntos operates three Sonrisa (meaning smile) clinics providing free dental restoration to underprivileged children.

The charity also runs oral health education sessions in surrounding schools, distributes toothbrushes and toothpaste and gives one-toone hygiene sessions to all its young patients.

\section{Mobile unit visits Blackpool}

Late last year homeless and vulnerable people in Blackpool received essential dental treatment on board a mobile dental unit operated by Dentaid. A team of volunteer dentists and dental nurses visited the Horizon service in Blackpool offering free treatment to 47 patients with a range of mental health conditions, those recovering from drug and alcohol addiction, the homeless and people who find it hard to access NHS dental services.

\section{Joint fundraising initiative}

Leading dental charities Bridge2Aid and Dentaid have launched a joint fundraising campaign to ensure more vulnerable people around the world can access dental care.

The two charities embarked on a 12-month fundraising initiative called 'Together Dental' in the autumn that will help both organisations expand their work and enable more people to access the dental treatment they so desperately need - both in the UK and abroad. Over the year there will be a programme of joint fundraising events and opportunities for individuals and businesses to donate and make a difference. All the money raised in the Together Dental appeal will be shared equally between Bridge2Aid and Dentaid.

This will enable Bridge2Aid to increase its programmes training rural health workers in East Africa and Dentaid to expand its work supporting dentists around the world while providing emergency care for refugees and people in the UK who find it hard to access dental treatment. Both charities will continue to run their popular volunteering programmes offering UK dental professionals the chance to use their skills overseas.

\section{Fluoride varnish donations}

Hundreds of children living in poor and remote communities in Cambodia will have healthier teeth thanks to Optident and volunteers working with Dentaid.

Optident and Ultradent donated 2,000 units of fluoride varnish for Dentaid to use on its projects around the world. The first batch was sent to Cambodia where volunteers visited slum areas near the capital Phnom Penh and community clinics in Kampong Cham. In addition to providing emergency dental treatment, the team also ran oral health education sessions, screening and fluoride varnish programmes. Over two weeks the team treated more than 350 people and they also supported Cambodian dental professionals who are working to improve access to dental care in the country. 